\title{
RESULTS OF SURGICAL TREATMENT OF NONUNION OF HUMERAL SHAFT FRACTURE WITH DYNAMIC COMPRESSION PLATE AND CANCELLOUS BONE GRAFTING
}

\author{
Olasinde Anthony Ayotunde ${ }^{1}$, Olumadiya Kehinde Sunday ${ }^{2}$, Adetan Olumatoyin ${ }^{1}$, Ogunlusi Johnson Dare $^{3}$
}

\section{ABSTRACT}

Objective: We evaluated the treatment of nonunion of humeral shaft fracture with dynamic compression plate from January 2002 to December 2009. Methods: Twenty-two patients were treated over the study period. Trauma was the predominant cause of injury in $86.4 \%$ of the patients. Results: Nonunion was atrophic in $81.8 \%$ and hypertrophic in $18.2 \%$ of the individuals. There was a primary injury of the radial nerve in $27.3 \%$ of the patients. All the participants had closed fracture at presentation, and $81.2 \%$ had received previous treatment from traditional bone setters and $18.8 \%$ had failure of the conservative cast management. The average time to healing was 16 weeks. Previous treatment from traditional bone setters significantly affected the time to fracture healing $(p<0.05)$. All fractures had successful union. Conclusion: It was concluded that dynamic compression plating remains an effective treatment option for nonunion of humeral shaft fracture.

Level of Evidence III, Retrospective Study.

Keywords: Humeral fractures/surgery. Humeral fractures/ therapy. Bone regeneration. Fracture fixation, internal.

Citation: Ayotunde OA, Sunday OK, Oluwatoyin A, Dare OJ. Results of surgical treatment of nonunion of humeral shaft fracture with dynamic compression plate and cancellous bone grafting. Acta Ortop Bras. [online]. 2012;20(4): 223-5. Available from URL: http://www.scielo.br/aob.

\section{INTRODUCTION}

Conservative nonoperative treatment with cast immobilization and bracing provide excellent results in over $90 \%$ of cases with union for isolated humeral shaft fractures. ${ }^{1,2}$ Nonunion of this fracture is a recognized complication of conservative management. In our environment where patients usually seek traditional bone setters, this remains one of the most common presentations of fractures. ${ }^{3}$

Varying results had been reported for different types of operative fixation with different associated morbidity relating to each method. The internal fixation methods and their common limitations include unlocked intramedullary nail with poor rotational stability, locked intramedullary nail with associated rotator cuff dysfunction and shoulder movement limitation, external fixation with pin tract infection and dynamic compression plating with wound infection and increased risk of iatrogenic or secondary radial nerve palsy. ${ }^{1-5}$ We evaluated the use of dynamic com- pression plate $(\mathrm{DCP})$ in the operative treatment of patients with nonunion of humeral shaft fractures.

\section{PATIENTS AND METHODS}

From January 2002 to December 2009, all the patients who presented humeral shaft fracture nonunion at the orthopedic unit of the Federal Medical Centre Owo, Ondo State, Nigeria, which is a tertiary healthcare institution were reviewed retrospectively. The inclusion criteria are humeral shaft fracture nonunion (which was defined in this study as no evidence of union after a six-month period), no previous surgical intervention, and minimum followup of 12 months. The humeral shaft was defined as the part of the humerus that is two centimeters below the surgical neck and $3 \mathrm{~cm}$ above the olecranon fossa. ${ }^{4}$ Nonunion was classified as defined by Paley et al. ${ }^{6}$ The outcome measure was time to union. Complications were also observed. Plain radiographs were taken to evaluate for union. The surgical approach to the

All the authors declare that there is no potential conflict of interest referring to this article.

1. Department of Orthopedic Surgery and Traumatology - Federal Medical Centre, Owo, Ondo State, Nigeria.
2. Department of Surgery Ladoke Akintola, University Teaching Hospital, Osogo Osum State Hospital, Nigeria.
3. Royal Victoria Hospital Castries, St Lucia, Nigeria.

Study conducted in the Orthopedic Surgery and Traumatology Department - Federal Medical Centre, Owo, Ondo State, Nigeria.

Mailing address: Department of Orthopedic Surgery and Traumatology, Federal Medical Centre, Owo, Ondo State, Nigeria.

Email olasindetony@yahoo.com/ olasindetony@gmail.com 
humerus was anterolateral for fractures in upper and middle third and posterior for those in the distal third. The pseudoarthrosis was excised, bone end nibbled until fresh bleeding was obtained and marrow location established; next the bone graft was harvested from iliac crest and used to pack around the bone end. Narrow $4.5 \mathrm{~mm}$ DCP was used for internal fixation. Successful union was defined as the appearance of bridge callus or bridging of the cortex with at least partial obliteration of the fracture site observed on antero-posterior and lateral radiographs. ${ }^{3}$ Demographic characteristics of the patients such as age, sex, site, fracture location and description, cause of fracture, previous treatment, and primary radial nerve palsy were recorded.

The results were analyzed using Statistical Package for Social Science version 15. The association test was done using Chi square and the level of significance was $p<0.05$

\section{RESULTS}

Twenty-two patients with humeral fracture nonunion were treated, representing $25.3 \%$ of all patients with humeral fractures seen in our hospital over the study period. The median age was 41.5 years with range of 23 to 76 years and male to female ratio of 1.8:1. The cause of injury was road traffic injury in $86.4 \%$ (19/22), fall $9.1 \%$ (2/22), and assault in 4.5\% (1/22). The previous treatment was from traditional bone setters in $81.8 \%$ (18/22) patients and failed conservative treatment from other hospital in $18.2 \%$ (4/22). Atrophic nonunion occurred in $81.8 \%$ (18/22) and hypertrophic nonunion in $18.2 \%(4 / 22)$ of the individuals (3/22). Only $7.2 \%(6 / 22)$ had primary radial nerve injury. All fractures were closed. The complications were wound hematoma in one patient and superficial wound infection also in one patient. The superficial wound infection resolved with daily wound dressing and antibiotics administration and spontaneous resolution of the hematoma occurred without the need for surgical drainage. The fracture characteristics and surgical approach are as in Table 1.

The average time to union was 16 weeks. Those with previous treatment from traditional bone setters had time to union of 20 weeks, with a time of 12 weeks for those with failed conservative treatment. This was statistically significant at $p<0.05$. (Table 2 ) The treatment by the traditional bone setter significantly affected the time to union after open reduction and internal fixation with narrow $4.5 \mathrm{~mm}$ dynamic compression plate. We followed the patients at two-week intervals in the first month and then every month for six months and once every two months for another six months.

\section{DISCUSSION}

The treatment of nonunion humeral shaft fracture continues to pose a challenge to orthopedic surgeons especially in developing countries where recent advances in the care of this fracture may not be readily available. There has been documented evidence of the superiority of plating of humeral shaft nonunion as reported by Kontakis and associates in their systematic review of literature. ${ }^{7}$

In this study the most common cause of injury was road traffic accident with male preponderance. This was not surprising since trauma has been described as an emerging epidemic in developing countries with the increasing use of automobiles. ${ }^{8}$
Table 1. Fracture characteristics and surgical approach

\begin{tabular}{|c|c|}
\hline \multicolumn{2}{|l|}{ Location } \\
\hline Proximal third & $9 \%(2 / 22)$ \\
\hline Middle third & $59 \%(13 / 22)$ \\
\hline Lower third & $31.8 \%(7 / 22)$ \\
\hline \multicolumn{2}{|l|}{ Pattern of fracture line } \\
\hline Transverse & $63.6 \%(14 / 22)$ \\
\hline Segmental & $18.2 \%(4 / 22)$ \\
\hline Comminuted & $13.6 \%(3 / 22)$ \\
\hline Oblique & $9.0 \%(1 / 22)$ \\
\hline \multicolumn{2}{|l|}{ Type of nonunion } \\
\hline $\mathrm{A} 1$ & $72.7 \%(16 / 22)$ \\
\hline A2 & $18.2 \%(4 / 22)$ \\
\hline B1 & $9.0 \%(2 / 22)$ \\
\hline \multicolumn{2}{|l|}{ Surgical approach } \\
\hline Anterolateral & $81.8 \%(18 / 22)$ \\
\hline Posterior & $18.2 \%(4 / 22)$ \\
\hline
\end{tabular}

Table 2. Previous treatment and time to union.

\begin{tabular}{c|c|c}
\hline Previous treatment & $\begin{array}{c}\text { Number of } \\
\text { patients }\end{array}$ & $\begin{array}{c}\text { Time to union in } \\
\text { weeks }\end{array}$ \\
\hline Traditional bone setter & 18 & 20 \\
\hline Failed conservative treatment & 4 & 12 \\
\hline Total & 22 & 32 \\
\hline
\end{tabular}

$p<0.05-x^{2}=2.333$. Confidence interval $95 \%, 0.76$ to 4.72 . Odds ratio 2.70 .

It was also observed that more than $80 \%$ of the patients in this study had previous treatment with traditional bone setters. The traditional bone setters are alternative practitioners involved in the care of fractures. Their mode of treatment of fractures includes among others the use of local splints made from raffia palms and bamboo sticks. These splints are usually too tight, jeopardizing the blood supply to the affected limb which may result in gangrene from compartment syndrome. ${ }^{9}$ Previous studies had shown several reasons for the patients' continued preference for alternative practitioners, and they only seek medical treatment when complications occur. ${ }^{10}$

The distribution of humeral fracture nonunion was predominantly of the atrophic type in more than $80 \%$ of the patients in this study. This was similar to the report by Tannura et al. in Brazil, where 15 of the 16 patients who had plate osteosynthesis for humeral nonunion had the atrophic type. ${ }^{11}$

Primary radial nerve palsy occurred in $27 \%$ of the patients in this study with $18 \%$ associated with fractures in the middle third of the humeral shaft. This finding was similar to the report by Tsai et al. ${ }^{12}$ This is probably due to the closeness of the proximal part of the radial nerve to the bone (in the radial groove) in this part of the humerus, making it vulnerable to injury.

Transverse fracture pattern was the most common associated 
with humeral shaft nonunion in this study. This contrasted with the report by Ring and associates who found that oblique or spiral fracture with butterfly fragment were the most commonly associated with nonunion of humeral shaft. They also found that nonunion was more common in proximal and middle third shaft fractures. This was consistent with our study where the predominant fracture site was in the middle third. ${ }^{13}$

The average time to union of all the fractures after plate osteosynthesis was 16 weeks. This was also consistent with the reports by other authors. ${ }^{9,14,15}$

Patients who had previous treatment with traditional bone setters had a time to union of 20 weeks and those without had 12 weeks. This was statistically significant. This difference may be due to the manner of application of the splint which is often too tight leading to progressive diminution of the blood supply to the affected limb. The reason for the inappropriate application of the splint is the lack of knowledge of anatomy of traditional bone setters. Other authors have documented the different complications associated with this splint. ${ }^{16,17}$

One of the banes of plate osteosynthesis is infection. This ranged from $1-5 \%^{18}$ except in the report by Changulani where it was as high as $20 \% .^{5}$

Superficial infection occurred in $4.5 \%$ of the patients in this study and was resolved with antibiotics.

\section{CONCLUSION}

In conclusion plate osteosynthesis of humeral fracture nonunion achieved successful union in all our patients.

\section{REFERENCES}

1. Sarmiento A, Zagorski JB, Zych GA, Latta LL, Capps CA. Functional bracing for the treatment of fractures of the humeral diaphysis. J Bone Joint Surg Am. 2000;82(4):478-86

2. Wallny T, Sagebiel C, Westerman K, Wagner UA, Reimer M. Comparative results of bracing and interlocking nailing in the treatment of humeral shaft fractures. Int Orthop. 1997;21(6):374-9.

3. Oginni LM Traditional bone setter in western Nigeria In: Biodun A. editor Cultural studies in Ile-Ife Institute of African Studies. Osun, Nigéria: Obafem Awolowo University lle Ife; 1995. p. 202-8.

4. Chao TC, Chou WY, Chung JC, Hsu CJ. Humeral shaft fractures treated by dynamic compression plates, Ender nails and interlocking nails. Int Orthop. 2005;29(2):88-91.

5. Changulani M, Jain UK, Keswani T. Comparison of the use of the humerus intramedullary nail and dynamic compression plate for the management of diaphyseal fractures of the humerus. A randomised controlled study. Int Orthop. 2007;31(3):391-5.

6. Paley D, Catagni MA, Argnani F, Villa A, Benedetti GB, Cattaneo R. Ilizarov treatment of tibial nonunions with bone loss. Clin Orthop Relat Res. 1989;(241):146-65.

7. Kontakis GM, Tosounidis T, Pagkalos J. Humeral diaphyseal aseptic non-unions: an Algorithm of management. Injury. 2007;38(Suppl 2):S39-49.

8. Adesunkanmi AR, Oginni LM, Oyelami AO, Badru OS. Epidemiology of childhood injury. J Trauma. 1998;44(3):506-12

9. Bickler SW, Sanno-Duanda B. Bone setter's gangrene. J Pediatr Surg. 2000;35(10):1431-3.
10. Ogunlusi JD, Oginni LM, Ikem IC. Normal leg compartment pressures in adult Nigerians using the Whitesides method. lowa Orthop J. 2005;25:200-2.

11. Tannura ARH, Oliveira DJ, Barros JW. Treatment of humeral shaft pseudoarthrosis with compression $3,5 \mathrm{~mm}$ AO plate plus thoracobrachial plaster cast. Acta Ortop Bras. 2002; 10(1):5-9.

12. Tsai $\mathrm{CH}$, Fong $\mathrm{YC}$, Chen $\mathrm{YH}$, Hsu CJ, Chang $\mathrm{CH}$, Hsu HC. The epidemiology of traumatic humeral shaft fractures in Taiwan. Int Orthop. 2009;33(2):463-7.

13. Ring D, Chin K, Taghinia AH, Jupiter JB. Nonunion after functional brace treatment of diaphyseal humerus fractures. J Trauma. 2007;62(5):1157-8.

14. Khan MS, Sahibzada AS, Khan MA, Sultan S, Younas M, Khan AZ. Outcome of plating, bone grafting and shortening of non-union humeral diaphyseal fracture. J Ayub Med Coll Abbottabad. 2005;17(2):44-6.

15. Hierholzer C, Sama D, Toro JB, Peterson M, Helfet DL. Plate fixation of ununited humeral shaft fractures: effect of type of bone graft on healing. J Bone Joint Surg Am. 2006;88(7):1442-7

16. Chapman JR, Henley MB, Agel J, Benca PJ. Randomized prospective study of humeral shaft fracture fixation: intramedullary nails versus plates. J Orthop Trauma. 2000;14(3):162-6.

17. Omololu B, Ogunlade SO, Alonge TO. The complications seen from the treatment by traditional bonesetters. West Afr J Med. 2002;21(4):335-7.

18. Reignier M, el Banna S, Hayez JP, Stelmaszyk J, Raynal P. Osteosynthesis of diaphyseal fractures of the humerus]. Acta Orthop Belg. $1987 ; 53(4): 485-91$ 